\title{
Author Correction: Conversion of human fibroblasts to angioblast-like progenitor cells
}

Leo Kurian, Ignacio Sancho-Martinez, Emmanuel Nivet, Aitor Aguirre, Krystal Moon, Caroline Pendaries,

Cecile Volle-Challier, Francoise Bono, Jean-Marc Herbert, Julian Pulecio, Yun Xia, Mo Li, Nuria Montserrat, Sergio Ruiz, Ilir Dubova, Concepcion Rodriguez, Ahmet M. Denli, Francesca S. Boscolo, Rathi D. Thiagarajan, Fred H. Gage,

Jeanne F. Loring, Louise C. Laurent and Juan Carlos Izpisua Belmonte

Correction to: Nature Methods https://doi.org/10.1038/nmeth.2255, published online 2 December 2012.

In the version of this article initially published, the recipients of grant RN2-00931 from the California Institute for Regenerative Medicine were listed as L.C.L., R.D.T., F.S.B. and J.F.L. The correct recipient is L.C.L. The error has not been corrected in the original article.

Published online: 7 February 2020

https://doi.org/10.1038/s41592-020-0745-8

(c) The Author(s), under exclusive licence to Springer Nature America, Inc. 2020

\section{Publisher Correction: Isolating neurons on the basis of function}

Rita Strack

Correction to: Nature Methods https://doi.org/10.1038/s41592-020-0744-9, published online 4 February 2020.

In the version of this article initially published, Donghoon Lee's name was misspelled Dungjoon Lee. The error has been corrected in the HTML and PDF versions of the article.

Published online: 18 February 2020

https://doi.org/10.1038/s41592-020-0773-4

(c) Springer Nature America, Inc. 2020 